\title{
BARRIERS ANALYSIS FOR SUSTAINABLE MANUFACTURING IMPLEMENTATION IN INDIAN MANUFACTURING INDUSTRIES USING INTERPRETIVE STRUCTURAL MODELLING
}

\author{
Priyanka Pathak \\ Research Scholar, Department of Mechanical Engineering \\ Jagannath University, Jaipur, India \\ M.P. Singh \\ Department of Mechanical Engineering \\ Jagannath University, Jaipur, India.
}

\begin{abstract}
The paper analyses SM barriers in Indian manufacturing industries. The analysis process begins with review of articles for identifying core barriers and developing a structural model using ISM. The purpose of using ISM is to find dependent and driving factors out of those barriers so that industries can get benefited by working in full capacity for removing the most hurdlers and keeping in mind the less ones and society can get benifited through proper implementation of SM in those industries.
\end{abstract}

Keywords: SM, ISM, Descriptive Analysis, Questionnaire Preparation.

Cite this Article: Priyanka Pathak and M.P. Singh, Barriers Analysis for Sustainable Manufacturing Implementation In Indian Manufacturing Industries Using Interpretive Structural Modelling, International Journal of Advanced Research in Engineering and Technology, 10(3), 2019, pp 27-35.

http://iaeme.com/Home/issue/IJARET?Volume=10\&Issue $=3$

\section{INTRODUCTION}

Manufacturing sector in India has developed in past passing through number of decades. The development from 1947 to 1960 's goes with settling of industrial foundation, then up to 1980 license issued permission based industrial set-ups, then 1990's govt. becomes liberal towards industries and competition increases throughout world [1]. At present CII: The Confederation of Indian Industry focuses on make in India projects for regular growth, efficiency improvement and competitiveness among manufacturers in industries [2]. Manufacturing has traditionally been associated with undesirable environmental side effects [3]. These side effects can be harnessed by growth and efficiency improvement, which is somewhere associated with environment and society and finances. All these three issues the environment, 
the society and the economy comes together, it achieves to sustainability [4]. Sustainable manufacturing implementations could made possible only by emphasizing its motivators, the drivers and reducing its obstacles, the barriers. Out of the bucket of barriers which one has to be chose as most hurdle creator, and to be removed first, is to be accessed through some techniques, one of them is to develop a structural model among these barriers for responsiveness. To determine relationship between dependents and drivers, Interpretative structural modeling (ISM) methodology has been used.

\section{IDENTIFICATION OF BARRIERS OF SM}

Different researchers in their articles had worked on barriers of SM (Sustainable Manufacturing) and similar terms, they gave them different names as barriers, hurdle factors, obstacles, key barriers, path- hinders, negative factors, reducing factors etc., all are considered under the term barrier. Before 2007, Bhardwaj S. et al. (1993) and Mihelcic J. et al. (2003) used terms for barriers but not specified any number and name. Beers D.V. et al. (2007) wrote about 7 different barriers, Luken R. et al. (2008) gave only 5 barriers, US Department of Commerce Report (2009) gave General description only and no specific details about barriers. Mudgal R. et al. (2010) discussed about 15 barriers, Mittal V. et al. (2012) provided 11 barrier names, Mathiyazhagan K. et al. (2013) mentioned maximum 26 path hinders in his article, Govindan K. et al. (2013) gave 5 barriers name, Bhanot N. et al. (2015) wrote for 15 barriers and Modha M. et al. (2018) uses 13 barrier names.

These different names and numbers are discussed with various academicians and industry professionals with many Brain Storming Sessions, and through series of sessions, identified core 12 Barriers of SM [5], which are listed below:

- Indefinite Return on Investments

- Less Enforcement by Public For Betterment

- Less Effective Law and Rulings

- Ineffective Legislation

- Ambiguity of Future Laws and Rulings

- Lesser Industrial Resources

- Perplexity in Technology

- Major Initial Expenditure

- Interposing Factors

- Inadequate Market Demand

- Unfamiliarity About System

- Less Interest Towards Sustainability

\section{INTERPRETATIVE STRUCTURAL MODELING (ISM)}

Interpretive Structural Modeling (ISM) is an interactive learning process. The method is interpretive in that the group's judgment decides whether and how items are related; it is structural relationships among elements of a system (Sage, 1977). However, the direct and indirect relationships between the factors describe the situation far more accurately than the individual factor taken in isolation. Therefore, ISM develops insights into collective understandings of these relationships. Jharkharia and Shankar (2005) applied ISM for understanding the barriers in IT - enablement of supply chains. Singh et al. (2007a, b) have 
used ISM methodology for implementation of AMTs and also for improving SMEs competitiveness. Singh (2011) have used ISM for finding structural relationship between different factors of supply chain coordination. The application of ISM typically forces managers to reassess perceived priorities and improve their understanding of the linkages among key concerns. The various steps involved in the ISM technique are [6]:

- Identification of elements, which are relevant to the problem or issues, this could be done by literature review or any group problem solving technique.

- Establishing a contextual relationship between elements with respect to which pairs of elements will be examined.

- Developing a structural self-interaction matrix (SSIM) of elements, which indicates pairwise relationship between elements of the system.

- Developing a reachability matrix from the SSIM, and checking the matrix for transitivity.

Transitivity of the contextual relation is a basic assumption in ISM which states that if element $\mathrm{A}$ is related to $\mathrm{B}$ and $\mathrm{B}$ is related to $\mathrm{C}$, then $\mathrm{A}$ will be necessarily related to $\mathrm{C}$.

- Partitioning of reachability matrix into different levels.

- Based on the relationships given above in the reachability matrix draw a directed graph (digraph), and remove transitive links.

- Convert the resultant digraph into an ISM, by replacing element nodes with statements.

- Review the ISM model to check for conceptual inconsistency, and make the necessary modifications.

Above described steps, which lead to the development of ISM model, are discussed below.

\subsection{Structural Self-Interaction Matrix (SSIM)}

For analyzing the criteria a contextual relationship of "leads to" is chosen here. For developing contextual relationships among variables, expert opinions based on management technique such as brainstorming was considered. For expressing the relationship between different factors for coordination and responsiveness in supply chain, four symbols have been used to denote the direction of relationship between the parameters $i$ and $j$ (here $i<j$ ):

- P: parameter $\mathrm{x}$ will lead to parameter $\mathrm{y}$;

- Q: parameter y will lead to parameter $\mathrm{x}$;

- $\mathrm{R}$ : parameter $\mathrm{x}$ and $\mathrm{y}$ will lead to each other; and

- S: parameters $\mathrm{x}$ and $\mathrm{y}$ are unrelated.

Table 1 Structural Self Interaction Matrix (SSIM)

\begin{tabular}{|c|l|l|l|l|l|l|l|l|l|l|l|l|l|}
\hline $\begin{array}{c}\text { Variable } \\
\text { no }\end{array}$ & Hurdle/Obstacles Factors (Barriers) & 12 & 11 & 10 & 9 & 8 & 7 & 6 & 5 & 4 & 3 & 2 & 1 \\
\hline H1 & Indefinite Return on Investments & R & Q & Q & Q & S & Q & P & Q & S & S & S & R \\
\hline H2 & Less Enforcement by Public For Betterment & P & P & P & S & S & S & S & R & P & P & R & \\
\hline H3 & Less Effective Law and Rulings & P & P & R & R & S & S & S & R & P & R & & \\
\hline H4 & Ineffective Legislation & P & P & R & R & S & S & S & R & R & & & \\
\hline H5 & Ambiguity of Future Laws and Rulings & P & P & R & R & S & S & S & R & & & & \\
\hline H6 & Lesser Industrial Resources & P & Q & Q & Q & Q & Q & R & & & & & \\
\hline H7 & Perplexity In Technology & S & S & S & R & P & R & & & & & & \\
\hline H8 & Major Initial Expenditure & P & S & Q & Q & R & & & & & & & \\
\hline H9 & Interposing Factors & P & P & R & R & & & & & & & & \\
\hline H10 & Inadequate Market Demand & P & P & R & & & & & & & & & \\
\hline H11 & Unfamiliarity About System & P & R & & & & & & & & & & \\
\hline H12 & Less Intrest Towards Sustainability & R & & & & & & & & & & & \\
\hline
\end{tabular}




\subsection{Initial Reachability Matrix}

The SSIM has been converted into a binary matrix, called the initial reachability matrix by substituting $\mathrm{P}, \mathrm{Q}, \mathrm{R}$ and $\mathrm{S}$ by 1 and 0 as per the case. The substitution of $1 \mathrm{~s}$ and $0 \mathrm{~s}$ are as per the following rules:

- If the (x,y) entry in the SSIM is $P$, the (x, y) entry in the reachability matrix becomes 1 and the $(\mathrm{j}, \mathrm{i})$ entry becomes 0 .

- If the (x,y) entry in the SSIM is $Q$, the $(x, y)$ entry in the reachability matrix becomes 0 and the $(\mathrm{j}, \mathrm{i})$ entry becomes 1 .

- If the (x,y) entry in the SSIM is R, the (x,y) entry in the reachability matrix becomes 1 and the (x,y) entry also becomes 1 .

- If the $(i, j)$ entry in the SSIM is $S$, the $(i, j)$ entry in the reachability matrix becomes 0 and the $(\mathrm{y}, \mathrm{x})$ entry also becomes 0 .

Following above rules, the initial reachability matrix for the critical success factors is shown in Table 2. After incorporating the transitivity as described in Step (4) of the ISM methodology, the final reachability matrix is shown in Table 3. In Table 3, the driving power and dependence of each variable is also shown. Driving power for each variable is the total number of variables (including itself), which it may help to achieve.

On the other hand, dependence is the total number of variables (including itself), which may help in achieving it. These driving power and dependencies will be later used in the classification of variables into the four groups of autonomous, dependent, linkage and drivers (independent).

Table 2 IRM for barriers

\begin{tabular}{|c|c|c|c|c|c|c|c|c|c|c|c|c|}
\hline Variable no & $\mathbf{1}$ & $\mathbf{2}$ & $\mathbf{3}$ & $\mathbf{4}$ & $\mathbf{5}$ & $\mathbf{6}$ & $\mathbf{7}$ & $\mathbf{8}$ & $\mathbf{9}$ & $\mathbf{1 0}$ & $\mathbf{1 1}$ & $\mathbf{1 2}$ \\
\hline H1 & 1 & 0 & 0 & 0 & 0 & 1 & 0 & 0 & 0 & 0 & 0 & 1 \\
\hline H2 & 0 & 1 & 1 & 1 & 1 & 0 & 0 & 0 & 0 & 1 & 1 & 1 \\
\hline H3 & 0 & 0 & 1 & 1 & 1 & 0 & 0 & 0 & 1 & 1 & 1 & 1 \\
\hline H4 & 0 & 0 & 0 & 1 & 1 & 0 & 0 & 0 & 1 & 1 & 1 & 1 \\
\hline H5 & 1 & 1 & 1 & 1 & 1 & 0 & 0 & 0 & 1 & 1 & 1 & 1 \\
\hline H6 & 0 & 0 & 0 & 0 & 0 & 1 & 0 & 0 & 0 & 0 & 0 & 1 \\
\hline H7 & 1 & 0 & 0 & 0 & 0 & 1 & 1 & 1 & 1 & 0 & 0 & 0 \\
\hline H8 & 0 & 0 & 0 & 0 & 0 & 1 & 0 & 1 & 0 & 0 & 0 & 1 \\
\hline H9 & 1 & 0 & 1 & 1 & 1 & 1 & 1 & 1 & 1 & 1 & 1 & 1 \\
\hline H10 & 1 & 0 & 1 & 1 & 1 & 1 & 0 & 1 & 1 & 1 & 1 & 1 \\
\hline H11 & 1 & 0 & 0 & 0 & 0 & 1 & 0 & 0 & 0 & 0 & 1 & 1 \\
\hline H12 & 1 & 0 & 0 & 0 & 0 & 0 & 0 & 0 & 0 & 0 & 0 & 1 \\
\hline
\end{tabular}

\subsection{Final Reachability Matrix}

The final reachability matrix is obtained by incorporating the transitivity as enumerated in Step (4) of the ISM methodology. This is shown in Table 3. In this table, the driving power and dependence of each factor are also shown. The driving power of a particular factor is the total number of factors (including itself), which it may help achieve while the dependence is the total number of factors, which may help achieving it. On the basis of driving power and dependencies, these factors will be classified into four groups of autonomous, dependent, linkage and independent (driver) factors. 
Barriers Analysis for Sustainable Manufacturing Implementation In Indian Manufacturing Industries Using Interpretive Structural Modelling

Table 3 FRM for barriers

\begin{tabular}{|c|c|c|c|c|c|c|c|c|c|c|c|c|c|c|}
\hline Variable no & & $\mathbf{1}$ & $\mathbf{2}$ & $\mathbf{3}$ & $\mathbf{4}$ & $\mathbf{5}$ & $\mathbf{6}$ & $\mathbf{7}$ & $\mathbf{8}$ & $\mathbf{9}$ & $\mathbf{1 0}$ & $\mathbf{1 1}$ & $\mathbf{1 2}$ & DRIVING POWER \\
\hline H1 & & 1 & 0 & 0 & 0 & 0 & 1 & 0 & 0 & 0 & 0 & 0 & 1 & 3 \\
\hline H2 & 0 & 1 & 1 & 1 & 1 & 0 & 0 & 0 & 0 & 1 & 1 & 1 & 7 \\
\hline H3 & 0 & 0 & 1 & 1 & 1 & 0 & 0 & 0 & 1 & 1 & 1 & 1 & 7 \\
\hline H4 & 0 & 0 & 0 & 1 & 1 & 0 & 0 & 0 & 1 & 1 & 1 & 1 & 6 \\
\hline H5 & 1 & 1 & 1 & 1 & 1 & 0 & 0 & 0 & 1 & 1 & 1 & 1 & 9 \\
\hline H6 & 0 & 0 & 0 & 0 & 0 & 1 & 0 & 0 & 0 & 0 & 0 & 1 & 2 \\
\hline H7 & 1 & 0 & 0 & 0 & 0 & 1 & 1 & 1 & 1 & 0 & 0 & 0 & 5 \\
\hline H8 & 0 & 0 & 0 & 0 & 0 & 1 & 0 & 1 & 0 & 0 & 0 & 1 & 3 \\
\hline H9 & 1 & 0 & 1 & 1 & 1 & 1 & 1 & 1 & 1 & 1 & 1 & 1 & 11 \\
\hline H10 & 1 & 0 & 1 & 1 & 1 & 1 & 0 & 1 & 1 & 1 & 1 & 1 & 10 \\
\hline H11 & 1 & 0 & 0 & 0 & 0 & 1 & 0 & 0 & 0 & 0 & 1 & 1 & 4 \\
\hline H12 & 1 & 0 & 0 & 0 & 0 & 0 & 0 & 0 & 0 & 0 & 0 & 1 & 2 \\
\hline DEPENDENCE & 7 & 2 & 5 & 6 & 6 & 7 & 2 & 4 & 6 & 6 & 7 & 11 & \\
\hline POWER & 7 & 2 & 5 & & & & & &
\end{tabular}

\subsection{Level Partition}

From the final reachability matrix, the reachability and antecedent set for each factor are found. The reachability set consists of the element itself and other elements to which it may help achieve, whereas the antecedent set consists of the element itself and the other elements which may help achieving it. Then the intersection of these sets is derived for all elements. The element for which the reachability and intersection sets are same is the top-level element in the ISM hierarchy. The top-level element of the hierarchy would not help in achieving any other element above their own. Once the top-level element is identified, it is separated out from the other elements. Then by the same process, the next level of elements is found. These identified levels help in building the final model. From 3, it is seen that the performance improvement is found at level I. Thus, it would be positioned at the top of the ISM hierarchy. This iteration is repeated till the levels of each factor are decided. These iterations are shown in Table 4. The identified levels aids in building the final model of ISM. And the final level set is shown in Table 5 .

Table 4 Level Partitions in ISM model for barriers

\begin{tabular}{|c|c|c|c|c|}
\hline Variables & Reachability Set & Antedecent Set & Interaction Set & Level \\
\hline $\mathrm{H} 1$ & $1,6,12$ & $1,5,7,9,10,11,12$ & 1,12 & \\
\hline $\mathrm{H} 2$ & $2,3,4,5,10,11,12$ & 2,5 & 2,5 & \\
\hline $\mathrm{H} 3$ & $3,4,5,9,10,11,12$ & $2,3,5,9,10$ & $3,5,9,10$ & \\
\hline $\mathrm{H} 4$ & $4,5,9,10,11,12$ & $2,3,4,5,9,10$ & $4,5,9,10$ & \\
\hline $\mathrm{H} 5$ & $1,2,3,4,5,9,10,11,12$ & $2,3,4,5,9,10$ & $2,3,4,5,9,10$ & \\
\hline $\mathrm{H} 6$ & 6,12 & $1,6,7,8,9,10,11$ & 6 & \\
\hline $\mathrm{H} 7$ & $1,6,7,8,9$ & 7,9 & 7,9 & \\
\hline $\mathrm{H} 8$ & $6,8,12$ & 8 & 8 & \\
\hline H9 & $1,3,4,5,6,7,8,8,9,10,11,12$ & $3,4,5,7,9,10$ & $3,4,5,7,9,10$ & \\
\hline $\mathrm{H} 10$ & $1,3,4,5,6,8,9,10,11,12$ & $2,3,4,5,9,10$ & $3,4,5,9,10$ & \\
\hline H11 & $1,6,11,12$ & $2,3,4,5,9,10,11$ & 11 & \\
\hline H12 & 1,12 & $1,2,3,4,5,6,8,9,10,11,12$ & 1,12 & $\mathrm{i}$ \\
\hline $\mathrm{H} 2$ & $2,3,4,5,10,11$ & 2,5 & 2,5 & \\
\hline $\mathrm{H} 3$ & $3,4,5,9,10,11$ & $2,3,5,9,10$ & $3,5,9,10$ & \\
\hline $\mathrm{H} 4$ & $4,5,9,10,11$ & $2,3,4,5,9,10$ & $4,5,9,10$ & \\
\hline H5 & $2,3,4,5,9,10,11$ & $2,3,4,5,9,10$ & $2,3,4,5,9,10$ & \\
\hline $\mathrm{H} 6$ & 6 & $6,7,8,9,10,11$ & 6 & ii \\
\hline $\mathrm{H} 7$ & $6,7,8,9$ & 7,9 & 7,9 & \\
\hline H8 & 6,8 & $7,8,9,10$ & 8 & \\
\hline $\mathrm{H} 9$ & $3,4,5,6,7,8,9,10,11$ & $3,4,5,7,9,10$ & $3,4,5,7,9,10$ & \\
\hline H10 & $3,4,5,6,6,8,9,10,11$ & $2,3,4,5,9,10$ & $3,4,5,9,10$ & \\
\hline H11 & 6,11 & $2,3,4,5,9,10,11$ & 11 & \\
\hline
\end{tabular}




\begin{tabular}{|c|c|c|c|c|}
\hline \hline H2 & $2,3,4,5,10,11$ & 2,5 & 2,5 & \\
\hline H3 & $3,4,5,9,10,11$ & $2,3,5,9,10$ & $3,5,9,10$ & \\
\hline 4 & $4,5,9,10,11$ & $2,3,4,5,9,10$ & $4,5,9,10$ & \\
\hline 5 & $2,3,4,5,9,10,11$ & $2,3,4,5,9,10$ & $2,3,4,5,9,10$ & \\
\hline H & $7,8,9$ & 7,9 & 7 & iii \\
\hline H8 & 8 & $7,8,9,10$ & $3,4,5,7,9,10$ & \\
\hline H9 & $3,4,5,7,8,9,10,11$ & $3,4,5,7,9,10$ & $3,4,5,9,10$ & iii \\
\hline H10 & $3,4,5,8,9,10,11$ & $2,3,4,5,9,10$ & 11 & \\
\hline H11 & 11 & $2,3,4,5,9,10,11$ & 2,5 & iv \\
\hline \hline H2 & $2,3,4,5,10$ & 2,5 & $3,5,9,10$ & iv \\
\hline H3 & $3,4,5,9,10$ & $2,3,5,9,10$ & $4,5,9,10$ & iv \\
\hline H4 & $4,5,9,10$ & $2,3,4,5,9,10$ & $2,3,4,5,9,10$ & iv \\
\hline H5 & $2,3,4,5,9,10$ & $2,3,4,5,9,10$ & 7,9 & iv \\
\hline H9 & 7,9 & 7,9 & $3,4,5,7,9,10$ & V \\
\hline H10 & $3,4,5,7,9,10$ & $3,4,5,7,9,10$ & $3,4,5,9,10$ & V \\
\hline H2 & $3,4,5,9,10$ & $2,3,4,5,9,10$ & 2,5 & \\
\hline H3 & $2,3,4,5,10$ & 2,5 & $3,5,9,10$ & \\
\hline
\end{tabular}

Table 5 Final Level-Set for barriers through Partitions

\begin{tabular}{|c|c|c|c|c|}
\hline Variables & Reachability Set & Antedecent Set & Interaction Set & Level \\
\hline H12 & 1,12 & $1,2,3,4,5,6,8,9,10,11,12$ & 1,12 & i \\
\hline H6 & 6 & $6,7,8,9,10,11$ & 6 & ii \\
\hline H8 & 8 & $7,8,9,10$ & 8 & iii \\
\hline H11 & 11 & $2,3,4,5,9,10,11$ & 11 & iii \\
\hline H4 & $4,5,9,10$ & $2,3,4,5,9,10$ & $4,5,9,10$ & iv \\
\hline H5 & $2,3,4,5,9,10$ & $2,3,4,5,9,10$ & $2,3,4,5,9,10$ & iv \\
\hline H7 & 7,9 & 7,9 & 7,9 & iv \\
\hline H9 & $3,4,5,7,9,10$ & $3,4,5,7,9,10$ & $3,4,5,7,9,10$ & iv \\
\hline H10 & $3,4,5,9,10$ & $2,3,4,5,9,10$ & $3,4,5,9,10$ & iv \\
\hline H2 & $2,3,4,5,10$ & 2,5 & 2,5 & v \\
\hline H3 & $3,4,5,9,10$ & $2,3,5,9,10$ & $3,5,9,10$ & v \\
\hline
\end{tabular}

\subsection{MICMAC Analysis or Classification of Factors}

First of all the full form of MICMAC Analysis is"Matriced' impacts croises-multiplication appliqué' and classment". In this the Leading power represents to all factors that help to gain Sustainability. Lacking power represents to all factors that helps in making them in place. In this analysis a graph/plot is made between leading(driving) and lacking(dependent) of various factors [7]. Figure 2 shows the Driving vs. dependence power diagram having bunches of factors in different quadrants with driving power at vertical axis and dependent power at horizontal axis. This figure 2 shows the various compatibilities between barriers of sustainability. It provides support data to higher management people to pursue with these factors for betterment of their industry in the field of sustainability. The plot shows the outcomes in four different zoned groups depending on either they have higher/lower driving power or higher/lower dependence power. 
Barriers Analysis for Sustainable Manufacturing Implementation In Indian Manufacturing Industries Using Interpretive Structural Modelling

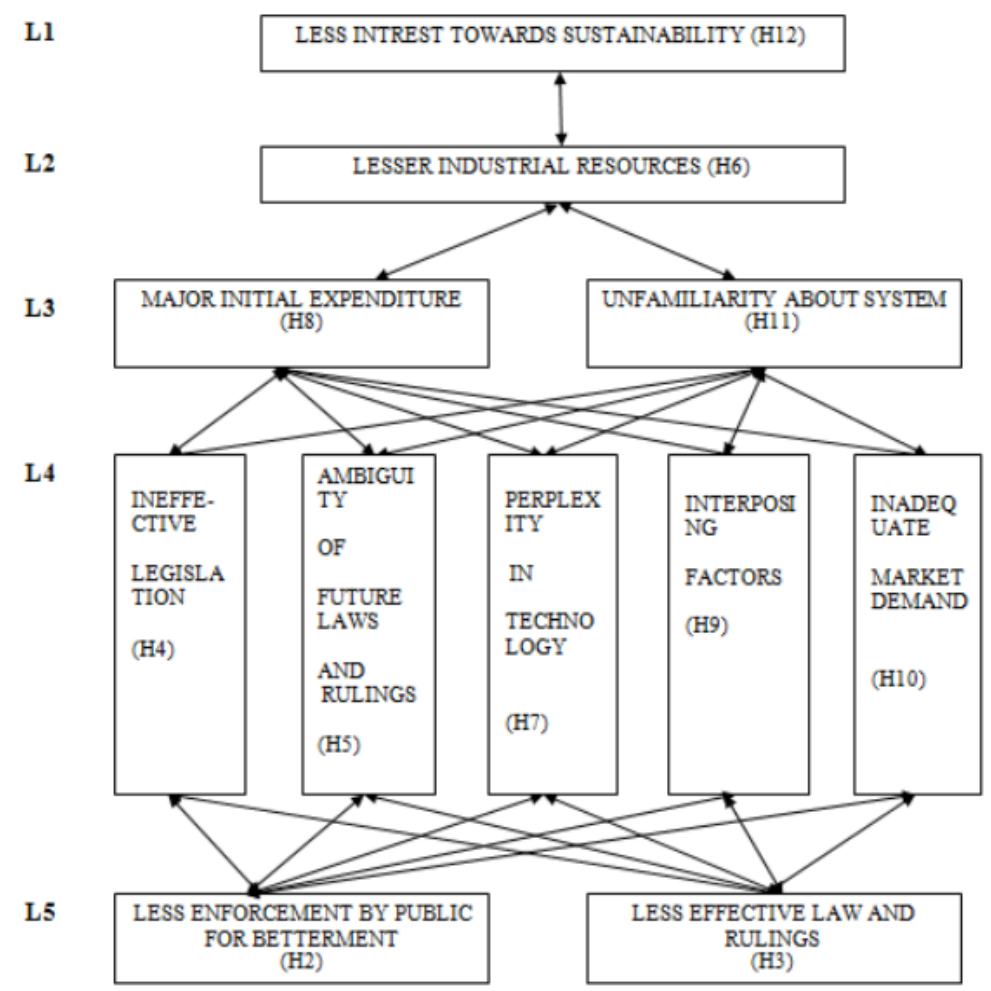

Figure 1 ISM-based relationship model for barriers

First Quarter named Autonomous factors or lower driving powered factors also lower dependency types have least influencing power at work. In this zone H6, H7, H8 factor are present, which means these have low driving as well as low dependent power, so top management has less to be worried about it while mitigating. Second Quarter named as dependent factors, in this zone three variables lying H1, H11, H12 as the name suggests these having more dependence than drive. They are not of much importance. Third Quarter named balance factors, here no variables fall in this zone. The factors whose dependence and driving power both are equally strong fall under this category and are very important for higher management, so here no bothering for top management. Fourth Quarter named left quarter is having factors with weak dependence and higher driving capability, these could be key for the management for betterment. Here $\mathrm{H} 2, \mathrm{H} 3, \mathrm{H} 4, \mathrm{H} 5, \mathrm{H} 9, \mathrm{H} 10$ factors falls under this zone in plot.

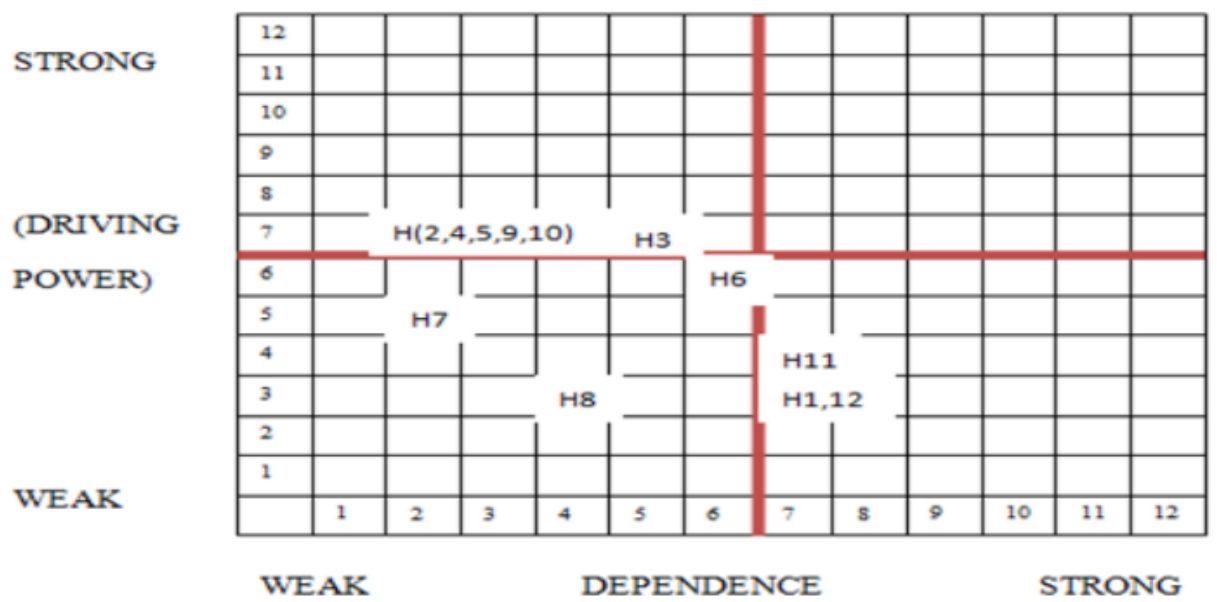

Figure 2 MICMAC Analysis of Barriers 


\section{CONCLUSIONS AND LIMITATIONS}

In this research 12 barriers identified through review of past articles and brain storming sessions of academicians and industrialists on the relative database. These 12 barriers are used to perform interpretive structural modeling and Micmac analysis.

In ISM, driving and driven relationship of these 12 variables is identified and a hierarchical ISM model is presented here as per the structural modeling calculations.

In Micmac Analysis, the four-quadrant relationship of these variables is shown after making a plot for driving power $\mathrm{v} / \mathrm{s}$ dependent power of variables.

The whole work gives importance level of these factors as which one more emphasized and which needs little attention for the industrialists and top management for successful implementation of sustainable manufacturing in their concerned workplaces.

Further in future similar work could be done for drivers of SM. Also, apart from manufacturing industries survey could be performed in other than manufacturing industries or ISM factors comparison can be made using group of similar industries.

\section{REFERENCES}

[1] www.cii.in/ sectors.aspx.

[2] www.cii.in/ SocialDevelopment.aspx.

[3] Pathak p., Singh M.P., Sharma P.; (2017); "Sustainable Manufacturing: An Innovation and Need for Future"; International conference on Recent Innovations in Engineering and Technology (ICRIET-18 FEB, 2017).

[4] Frosch, R. A. and Gallopoulos, N. E. (1989), "Strategies for Manufacturing", Scientific American, vol. 261, no. 3, pp. 144-152.

[5] Pathak p., Singh M.P.; (2019); "Descriptive Analysis through Survey for Sustainable Manufacturing"; International Conference on Advancements in Computing and Management"; (ICACM- 13 April,2019).

[6] http://shodhganga.inflibnet.ac.in/bitstream/10603/26752/13/13_chapter\%206.pdf

[7] Chauhan A. S., Badhotiya G.K., Soni.G., Ratore A.P.S.;(2017);” Analysis of success factors for a new product development initiative in Indian automotive industry: an ISM approach"; International Journal of Advanced Operations Management; vol 9, no 4, pp 1-18.

[8] Rachuri S., Sriram R. D., Narayanan A., Sarkar P., Lee J. H., Lyons K. W. and Kemmerer (Eds.) S. J.;(2010); "Sustainable manufacturing: metrics, standards, and infrastructure -Workshop Report"; NISTIR 7683.

[9] Ravi, V. and Shankar, R.; (2005); "Productivity improvement of a computer hardware a supply chain"; International Journal of Productivity and Performance Management; Vol. 54, No. 4, pp.239-255.

[10] Luthra S., Qadri M. A., Garg D., Haleem A.;(2014); "Identification of critical success factors to achieve high green supply chain management performances in Indian automobile industry"; International Journal of Logistics Systems and Management; vol. 18 no. 2, pp. 170-199.

[11] Faisal, M.N., Banwet, D.K. and Shankar, R.; (2006); "Supply chain risk mitigation: modeling the enablers"; Business Process Management Journal; Vol. 12, No. 4, pp.535-552.

[12] 12. Theyel, G.; (2000); "Management practices for environmental innovation and performance"; International Journal of Operations \& Production Management; Vol. 20, No. 2, pp.249-266.

[13] Mittal VK, Sangwan KS, Herrmann C, Egede P. Comparison of Drivers and Barriers to Green Manu- facturing: A Case of India and Germany. In: Nee, Song and Ong, editors. Re-engineering Manufacturing for Sustainability 2013, In proceedings of the 20th CIRP International Conference on Life Cycle Engineering (LCE 2013), Singapore, pp. 723- 728. 
[14] Alvi, A. U. and Labib, A. W. (2001), "Selecting next generation manufacturing paradigms - An analytic hierarchy process-based criticality analysis", Proceedings of the Institution of Mechanical Engi- neers, Part B: Journal of Engineering Manufacture, vol. 215, no. 12, pp. 1773-1786.

[15] Welford, R. (2003), "Beyond systems: A vision for corporate environmental management for the future", International Journal of Environment and Sustainable Development, vol. 2, no. 2, pp. 162173.

[16] 16. Bhamra, T. A. (2004), "Ecodesign: the search for new strategies in product development", Proceedings of the Institution of Mechanical Engineers, Part B: Journal of Engineering Manufacture, vol. 218, no. 5, pp. 557-569.

[17] Ayres, R. U. (1989), "Industrial Metabolism”, in Ausubel, J. H. and Sladovich, H. E. (eds.) Technology and Environment, National Academy Press, Washington D.C., pp. 23-49.

[18] Kannan G. et al.;(2008);” Analysis and selection of green suppliers using interpretative structural modelling and analytic hierarchy process"; Int. J. Management and Decision Making, Vol. 9, No. 2.

[19] Luken R. et al.;(2008);” Drivers for and barriers to environmentally sound technology adoption by manufacturing plants in nine developing countries"; Journal of Cleaner Production 16S1 (2008) S67-S77.

[20] Dr. V. Antony Joe Raja and R. Anbu Ranjith Kumar, A Study on Effectiveness of Performance Appraisal System In Manufacturing Industries In India. The Key to Lean Performance: Implementing a Daily Shop-Floor Control System Using Standardization and Visual Management. International Journal of Advanced Research in Management, 7(1), 2016, pp. 44-50

[21] A. Suresh and Dr. N. Somasundaram, A Study on Impact of Barcode and Radio Frequency Identification Technology on Maximized Productivity in Manufacturing Industries at Sipcot, Chennai. International Journal of Management, 8(1), 2017, pp. 13-20

[22] Dr Z Mallick, Mr Shahzad Ahmad, Lalit Singh Bisht, Barriers and Enablers in Implementation of Lean Six Sigma in Indian Manufacturing Industries. International Journal of Advanced Research in Management, 3(1), 2012, pp. 11-19

[23] Gunji Venkata Punna Rao, S. Nallusamy and M. Rajaram Narayanan, Augmentation of Production Level using Different Lean Approaches in Medium Scale Manufacturing Industries, International Journal of Mechanical Engineering and Technology 8(12), 2017, pp. 360-372

[24] Rethy B. Menon, Aparna K.Jand Tenzin Chonzom, "Does Ecopreneurship Play a Prominent Platform for Business Sustainability: An Exploratory Study with Reference to Cosmetic Manufacturing Industries in Mysuru City”, International Journal of Mechanical Engineering and Technology,9(11), 2018, pp. 741-747 